\title{
On aphorisms
}

\section{'The art is long and life is short.'}

Here is a fundamental truth about the human condition. It can be quoted in reference to any field of human endeavour, and, if you want to appear particularly well educated, you can quote it in sonorous Latin: ars longa, vita brevis.

As such it appeared as a graffito on the walls of ancient Rome, and recently, to a colleague's surprise, on a wall in East London.

But I guess that not many people who quote, or scribble it, know that the Art in question is medicine, and that they are partially quoting the first aphorism of Hippocrates. Quoted in full, it becomes clear that not only is the art medicine, but specifically it is some sort of intervention medicine, perhaps bone-setting or surgery:

\begin{abstract}
'Life is short and the art long: the crisis fleeting: experience perilous and decision difficult. The physician must not only be prepared to do what is right himself, but also to make the patient, the attendants and externals cooperate.' 1
\end{abstract}

Most of us would recognise the sentiments: in one paragraph they sum up the challenges facing doctors. All the more astonishing then, that it was written 2300 years ago.

An aphorism is a 'short pithy saying expressing a general truth'. It is drawn from experience, and so the attribution is important: it matters who said it as well as what was said. But aphorisms evolve in oral transmission: they don't live on the page, they live in speech. They were particularly important in pre-literate societies where learning was transmitted orally rather than by text, and when writing arrived they were codified and written down as 'wisdom-literature'. As they are copied and translated and spoken they mutate to remain fresh and sharp (note the inversion of 'The art' and 'life' in the two quoted versions above). The best aphorisms have a memorable, poetic quality. Some analysts even consider them to be a branch of poetry in their own right. These are the haiku of medicine.

Hippocrates started it all. It is nice to think of him as the 'father of medicine': the archetype physician who left us 80 extraordinary textbooks. History is never that neat, however, and the 'Works of Hippocrates' would be better described as 'the accumulated manuscripts of the library of the medical school at Kos named after a doctor called Hippocrates who may or may not have existed around about 300 BCE' (which is, admittedly, a bit less snappy). The books are of various ages and authorship. Romantics can choose their favourite manuscripts to be the ones 'genuinely written by Hippocrates'. I choose the Aphorisms: 400 pithy, humane maxims to teach the apprentice doctor. In them I hear the voice of an individual with whom I want to identify: a cautious, empirical physician, practicing holistically, aware of the limits of his knowledge, and deeply committed to teaching.

When I was trained as an adult educator, I learned a lot about educational theory, mostly expressed by diagrams consisting of boxes of abstract nouns connected by arrows. The emphasis was on evidence-based practice, not on passing on the wisdom-literature of older colleagues. In my teaching practice, however, the boxes of nouns haven't proved that useful. My preferred 'teaching style' needs aphorisms. If short, pithy maxims stick in my head, surely they will stick in the heads of my students? And if the aphorism can be attributed to someone famous, there is a secondary gain: subliminally I become associated in my apprentices' minds with the great physicians of the past, which can't be a bad thing. I might even start using Latin. But you have to be careful about excessive respect for our forbears: Medieval physicians could pass their Finals by delivering a dissertation on a book of Hippocrates, demonstrating debating skills and classical education, rather than practicing real medicine on smelly, ungrateful patients. Scholasticism reached absurd levels, and physicians would not believe the evidence of their own eyes if it were not supported by ancient texts. Hippocrates, the observer and empiricist, would have been ashamed of that legacy.

It is the oral-poetic nature of a good aphorism that flash-welds it into the memory. Read on the page it may only generate a passing smile. Heard at the apposite moment on a ward round, it will remain fixed for decades. Admittedly some of the more esoteric ones stuck in my head have not proved to be all that useful: for the last 30 years I have remembered to 'beware the man with the glass eye and the large liver'. It refers to late metastasis of malignant melanoma of the retina, which I have never seen, and may not see before I retire, but something about the melodramatic warning and startling juxtaposition has kept it fresh in my head, long after I have forgotten biochemical pathways and attachments of muscles.

So what aphorisms do I find useful when teaching?

'The art of medicine is to keep the patient entertained while nature effects a cure.' (Francois-Marie Arouet 'Voltaire', 1694-1778)

Voltaire hated doctors, rightfully suspecting them of doing more harm than good, but in his cynicism he shrewdly encapsulates the expectant management of the good primary care physician.

***
'Common things occur commonly
and rare things occur rarely.'
(Anonymous)

A mantra for general practice. Getting a feel for prevalence underpins our ability to identify likely differential diagnoses. One day it will be porphyria, but probably not today.

$$
\text { *** }
$$


'To cure sometimes, to relieve often, and to comfort always.'

Cited as a 15th century folk saying, but transcendent poetry, and the rallying cry of the palliative care profession. Hippocrates might comment, 'I wish l'd said that'.

$$
\text { *** }
$$

'All women are pregnant until proven otherwise.' (Personal communication: Professor Harold Ellis, CBE FRCS Emeritus Professor Surgery University London, 1979)

Hands up those who've had a surprise when they forgot this one.

$$
* * *
$$

'If you don't put your finger in it, you'll put your foot in it.'

Most of us have omitted a digital rectal examination at some point and regretted it. The blunt vernacular language suits the subject matter. I suspect that I first heard this one attributed to Professor Harold Ellis in London in the 1970s, but did he coin it or quote someone earlier?

$$
\text { *** }
$$

\section{'Neurology is all in the history.'}

This one needs a bit of work on the poetry, but it encapsulates a precept that young doctors take time to learn: early neurological disease is unlikely to have physical signs, so if you are not clear what you are looking for from the history, you will not be enlightened by exhaustive neurological examination and investigation. This is an orphan aphorism: it needs a great neurologist to adopt it, polish the language and popularise it. Any nominations?

$$
\text { *** }
$$

'Persons who are naturally very fat are apt to die earlier than those who are slender.'

Guess who? It's Hippocrates again, 2300 years before Framingham. ${ }^{1}$
'The five tumours that commonly metastasise to bone are the five Bs: bronchus, breast, byroid, brostate, and bidney.'

I'm sure that this one was coined by $\mathrm{Dr}$ Rob Buckman an oncologist in Toronto in a personal communication in 2007. The faux-alliteration and the parody of all those interminable lists make it unforgettable.

In general practice we are the natural heirs of Hippocrates and his style of medicine, so we have a rich heritage. That hasn't stopped me acquiring a few new ones specific to the craft.

$$
\text { *** }
$$

\section{'Beware the patient with thin notes.' (Anonymous)}

Not so useful now that we all have computers, but a sound maxim: someone who seldom visits the GP will have thin notes, and when they do come, it will be serious.

'Always turn the car round before you go into the house on a visit.' (Personal communication: Dr St John Pennet, retired GP, Bishops Castle, Shropshire, 1989)

... presumably to avoid the embarrassment of reversing over the cat, or perhaps for the occasion when you need to make a quick getaway.

$$
\text { *** * }
$$

'There are five reasons for referring a patient to hospital: to diagnose, to reassure, to manage, to cure, and to punish.' (Anonymous)

Sometimes the only cure for someone who insists that they are ill is to take them at their word.

There are many new fields of medicine, and I suspect that they are generating their own vernacular poetry of aphorisms in the wards and clinics. I hope that the relevant ones will spread into general practice usage (email me any good ones). In fact, dear colleagues, here is your chance for immortality. Eponyms are being suppressed, you're probably too late for an Axiom, Postulates are getting a bit thin on the ground and Tudor-Hart got the last Law. But you have a chance of professional fame if you coin a good aphorism. Be even more public-spirited, and immortalise the doctors who taught you, by keeping their aphorisms alive.

Hippocrates would be proud of you.

\section{Quentin Shaw}

\section{REFERENCE}

1. Hippocrates. Volume IV. Trans. Jones WHS. Cambridge, MA: Loeb Classical Library, 1931.

DOI: 10.3399/bjgp09X473312 